\title{
NORMAS GERAIS E COMPETÊNCIA CONCORRENTE Uma exegese do art. 24 da Constituição Federal
}

\author{
Tércio Sampaio Ferraz Júnior \\ Professor Titular do Departamento de Filosofia e Teoria Geral do Direito da \\ Faculdade de Direito da Universidade de São Paulo
}

\begin{abstract}
Resumo:
A noção de norma geral não conhece, na doutrina, uma definição adequadamente operacional. Por ser, logicamente, termo correlativo, geral só se define em face do seu oposto e vice-versa. Levando-se em conta que generalidade, no caso das normas, pode ser um atributo ligado tanto ao número de destinatários quanto à matéria normativa, pode-se perceber que o assunto, na ordem constitucional, exige análise acurada.
\end{abstract}

\begin{abstract}
:
The notion of general now does not have, in the science of law, a proper definition. Since general is logically a correlative term, it can only be defined in accordance with its opposite and vice-versa. Taking into account that generality with regards to norms is something that can be-related to the number of people targeted by them, as well as to the normative subject, it can be noticed that this matter, in the constitutional field, demands an accurate analysis.
\end{abstract}

1. É de longa data que a expressão normas gerais vem trazendo problemas doutrinários aos intérpretes da Constituição. Isto, por exemplo, no que se referia ao correto entendimento, na Constituição de 1946, da expressão normas gerais de direito financeiro (art. $8^{\circ}, \mathrm{XV}$, b), ou, na Constituição de 1967, da expressão normas gerais de direito tributário (art. $19, \S 1^{\circ}$ ) que aparecia também na Emenda n. 1 de 1969 no art. $18, \S 1^{\circ}$ Para além das divergências sobre o conteúdo destas normas, a questão formal ocupava igualmente uma posição destacada nas disputas.

2. Neste último aspecto, o trabalho pioneiro é o de Carvalho Pinto (Normas Gerais de Direito Financeiro, ed. Prefeitura do Município de São Paulo, 1949, p. 24), que ensaia uma delimitação por via negativa, conduzindo o raciocínio com base no argumento a contrario, nos seguintes termos: "a. não são normas gerais as que objetivem especialmente uma ou algumas dentre várias pessoas congêneres de direito público, participantes de determinadas relações jurídicas; b. não são normas 
gerais as que visem, particularizadamente, determinadas situações ou institutos jurídicos, com exclusão de outros, da mesma condição ou espécie; c. não são normas gerais as que se afastem dos aspectos fundamentais ou básico, descendo a pormenores ou detalhes" (grifei).

3. Na Constituição de 1988, a questão torna-se agudamente significativa, em face do conjunto de regras estabelecidas nos parágrafos do art. 24 . É o seguinte o teor do art. 24:

“Art. 24. Compete à União, aos Estados e ao Distrito Federal legislar concorrentemente sobre:

I - direito tributário, financeiro, penitenciário, econômico e urbanístico,

II - orçamento;

III - juntas comerciais;

$I V$ - custas dos serviços forenses;

$V$ produção e consumo;

VI florestas, caça, pesca, fauna, conservação da natureza, defesa do solo e dos recursos naturais, proteção do meio ambiente e controle da poluição;

VII - proteção ao patrimônio histórico, cultural, artístico, turístico e paisagístico;

VIII - responsabilidade por dano ao meio ambiente, ao consumidor, a bens e direitos de valor artístico, estético, histórico, turístico e paisagístico;

LX - educação, cultura, ensino e desporto;

$X$ - criação, funcionamento e processo do juizado de pequenas causas;

$X I$ - procedimentos em matéria processual;

XII previdência social, proteção e defesa da saúde;

XIII - assistência juridica e defensoria pública;

XIV proteção e integração social das pessoas portadoras de deficiência;

$X V$ - proteção à infância e à juventude;

XVI - organização, garantias, direitos e deveres das polícias civis.

$\S l^{\circ}$ - No âmbito da legislação concorrente, a competência da União limitar-se-á a estabelecer normas gerais.

$\S 2^{\circ}$ - A competência da União para legislar sobre normas gerais não exclui a competência suplementar dos Estados. 
$\S 3^{\circ} \quad$ Inexistindo lei federal sobre normas gerais, os Estados exercerão a competência legislativa plena, para atender a suas peculiaridades.

$\S 4^{\circ}$ - A superveniencia de lei federal sobre normas gerais suspende a eficácia da lei estadual, no que lhe for contrário."

$\mathrm{O} \S 1^{\circ}$ traz, como regra geral, que, no âmbito da legislação concorrente, a competência da União deve limitar-se ao estabelecimento de normas gerais. A contrario sensu, a competência dos Estados e do Distrito Federal, nas matérias enumeradas nos dezesseis incisos do caput, é para o estabelecimento de normas particulares, devendo-se lembrar que o $\S 2^{\circ}$, ao conferir à União a competência para legislar sobre normas gerais, determina que não fica excluída a "competência suplementar" dos Estados.

4. Faz mister examinar estes conceitos. Principiemos pela noção de competência. Trata-se de uma forma de poder jurídico, isto é, de exercício impositivo de comportamentos e relação de autoridade regulado por normas. Estas normas, segundo Alf Ross (Logica de las Normas, 1968), são "normas de competência", em oposição a "normas de conduta" Ao estabelecer esta forma de poder jurídico, a norma de competência enuncia também (ou lhes alude) as condições necessárias para o exercício: as que delimitam qual o sujeito qualificado (competência pessoal), qual o procedimento (competência procedimental) e o alcance possível em face dos sujeitos passivos, sua situação e seu tema (competência material). Fora destes limites, os atos de exercício são nulos e a norma criada for força deles é inválida. As normas de competência que estatuem as chamadas competências públicas criam um poder heterônomo, isto é, cujo exercício é um munus publicum qualificado, isto é, restrito para certos e determinados sujeitos, e, por ser qualificado, não-transferível, podendo apenas e eventualmente ser delegado (sobre competência cf. Ferraz Jr., Competência Tributária Municipal, Revista de Direito Tributário, Ano 14, julho-setembro de 1990, n. 53, p. 82).

5. As competências do Estado federal são repartidas horizontal e verticalmente. A repartição horizontal ocorre pela atribuição a cada ente federativo de uma área reservada, que lhe cabe, então, disciplinar em toda a sua extensão. A repartição vertical distribui uma mesma matéria em diferentes níveis (do geral ao particular) e a reparte entre os entes federativos. No primeiro caso (horizontal), as competências ou são comuns ou são privativas. No segundo (vertical), temos a competência concorrente. Para disciplinar a competência concorrente há duas 
técnicas conhecidas: a cumulativa, pela qual os entes podem avançar na disciplina das matérias desde que o que lhes é considerado superior não o faça (não há limites prévios, mas a regra da União prevalece, em caso de conflito); a não-cumulativa, em que, previamente, as matérias estão delimitadas por sua extensão (normas gerais e particulares) (cf. Manoel Gonçalves Ferreira Filho, Comentários à Constituição Brasileira, $6^{a}$ ed., São Paulo, Saraiva, 1986, p. 98 ss.).

6. A Constituição Federal de 1988 conhece tanto a repartição horizontal quanto a vertical. No plano horizontal, o art. 22 enuncia o campo de competência privativa da União; o art. 30 , o da competência privativa dos Municípios; o art. 25, $\S 1^{\circ}$ : a competência (privativa) residual dos Estados; e o art. 23, a competência comum da União dos Estados, Distrito Federal e Municípios. Por sua vez, por exemplo, o art. 5०, XXII ("O Estado promoverá, na forma da lei, a defesa do consumidor"), não instaura, por sua índole (rol dos direitos fundamentais), uma competência comum, mas um dever comum ao qual corresponde uma competência concorrente nos moldes do art. 24.

7. Pelo art. 24 , a repartição vertical é não-cumulativa, determinando-se previamente que a União "limitar-se-á" a legislar sobre normas gerais quanto às matérias que enumera. É cumulativa no caso do $\S 4^{\circ}$ que determina a prevalência de norma geral da União, superveniente a norma geral contida em lei estadual. A distinção entre normas gerais e particulares aponta, de início, para um problema de natureza lógica, referente à quantidade das proposições. Do ponto de vista da lógica jurídica, as normas podem ser, quanto à quantidade, gerais, particulares ou individuais. Esta distinção pode ser vista quanto aos destinatários ou quanto aos conteúdos da norma. Uma norma é geral, quanto aos destinatários, quando se aplica à universalidade deles, sem distinções. Melhor seria, neste caso, chamá-la de norma universal. A contrario sensu, ela será particular, quando se destina a uma coletividade ou categoria de destinatários. Melhor se fala aqui em norma especial. Por fim, é individual a que se destina a um único endereçado. Quanto aos conteúdos, as normas são gerais quando a matéria prescrita se reporta a toda e qualquer ocorrência da espécie (facti species, fato gerador, hipótese de incidência). Particular, quando a matéria assinala apenas um grupo ou parte da espécie. Individual, ou melhor, singular, quando sua matéria delimita um único caso.

Esquematicamente, temos:

Quanto ao destinatário: normas universais (todos) normas especiais (alguns) 


\begin{abstract}
normas individuais (um único)
Quanto ao conteúdo: normas gerais (totalidade dos casos)

normas particulares (alguns casos)

normas singulares (um único caso)
\end{abstract}

Assim, em princípio, do ponto de vista lógico, quando o texto constitucional atribui à União competência para legislar sobre "normas gerais" a linguagem constitucional pode estar tratando de normas gerais pelo conteúdo, ou de normas universais, isto é, gerais pelo destinatário, cabendo aos Estados e Distrito Federal, correspondentemente, a competência para o estabelecimento de normas especiais e individuais (conforme o destinatário) ou particulares e singulares (conforme o conteúdo).

8. A lógica, porém, ajuda mas não resolve inteiramente a questão interpretativa. A expressão constitucional - normas gerais exige também uma hermenêutica teleológica. Sob o mencionado aspecto lógico sempre será possível dizer que, por exemplo, quanto ao conteúdo, normas gerais prescrevem princípios, diretrizes sistemáticas, temas que se referem a uma espécie inteira e não a alguns aspectos, mas isto é insuficiente para reconhecer quando estamos diante de uma norma geral ou de uma particular. Sempre restarão dúvidas, no caso concreto, para aplicar o critério estritamente lógico-formal. Deste modo, para o intérprete, a necessidade de se analisar o conteúdo num contexto finalístico se impõe. Assim, do ângulo teleológico, a distinção há de se reportar ao interesse prevalecente na organização federativa. A federação brasileira, já pelo disposto no caput do art. $1^{\circ}$, já pela ênfase na solidariedade, na redução das desigualdades regionais, na garantia de um desenvolvimento nacional (art. $3^{\circ}$ ) aponta muito mais para um federalismo do tipo cooperativo, que exige a colaboração dos entes federativos e confere, correspondentemente, menor importância à separação e independência recíproca entre eles. Até formalmente, a mudança da expressão "Estados Unidos do Brasil" usada ainda em 1946, para "República Federativa do Brasil" mostra, historicamente, este objetivo.

9. Ora, o federalismo cooperativo vê na necessidade de uniformização de certos interesses um ponto básico da colaboração. Assim, toda matéria que extravase o interesse circunscrito de uma unidade (estadual, em face da União; municipal, em face do Estado) ou porque é comum (todos têm o mesmo interesse) ou porque envolve tipologias, conceituações que, se particularizadas num âmbito 
autônomo, engendrariam conflitos ou dificuldades no intercâmbio nacional, constitui matéria de norma geral.

10. Pelo art. $24, \S 2^{\circ}$ e $\S 3^{\circ}$, duas situações, ademais, merecem atenção. $\mathrm{O} \S 3^{\circ}$ regula o caso de inexistência de lei federal sobre normas gerais, ou seja, de lacuna. A Constituição Federal, ocorrendo a mencionada inexistência, autoriza o Estado federado a preenchê-la, isto é, a legislar sobre normas gerais, mas apenas para atender a suas peculiaridades. O Estado, assim, passa a exercer uma competência legislativa plena, mas com função colmatadora de lacuna, vale dizer, apenas na medida necessária para exercer sua competência própria de legislador sobre normas particulares. Ele pode, pois, legislar sobre normas gerais naquilo em que elas constituem condições de possibilidade para a legislação própria sobre normas particulares. Tais normas gerais estaduais com função colmatadora por isso mesmo só podem ser gerais quanto ao conteúdo, mas não quanto aos destinatários: só obrigam nos limites da autonomia estadual.

11. Diferente, a nosso ver, é a situação do $\S 2^{\circ}$, em que, inobstante a competência privativa da União e até supondo-a exercida (não há, pois, inexistência ou lacuna de normas gerais), garante aos Estados a chamada competência suplementar. Esta competência, aliás, também é conferida aos Municípios (art. 30 II) que, no entanto, não participam da competência concorrente. Que significa, então, o constituinte com esta competência?

12. A competência suplementar não se confunde com o exercício da competência plena "para atender a suas peculiaridades" conforme consta do $\S 2^{\circ}$, que é competência para editar normas gerais em caso de lacuna (inexistência) na legislação federal. Não se trata, pois, de competência para editar normas gerais eventualmente concorrentes. Se assim fosse, o $\S 3^{\circ}$ seria inútil ou o $\S 3^{\circ}$ tornaria inútil o $\S 2^{\circ}$ Além disso, é competência também atribuída aos Municípios que estão, porém, excluidos da legislação concorrente. Isto nos leva a concluir que a competência suplementar não é para a edição de legislação concorrente, mas para a edição de legislação decorrente, que é uma legislação de regulamentação, portanto de normas gerais que regulam situações já configuradas na legislação federal e às quais não se aplica o disposto no $\S 4^{\circ}$ (ineficácia por superveniência de legislação federal), posto que com elas não concorrem (se concorrem, podem ser declaradas inconstitucionais). É pois competência que se exerce à luz de normas gerais da União e não na falta delas. 
13. O problema, aqui não resolvido, é o que deve fazer o Município em caso de inexistência de normas gerais, da União ou do Estado. Se ele não pode exercer a competência plena com função colmatadora, pode, não obstante, editar as suas normas particulares? Por exemplo, na ausência de legislação estadual, pode ele criar, organizar e suprimir distritos (art. 30 - IV)? A nosso ver sim, mas não por intermédio da edição da norma geral que lhe falta (exercício de competência plena com função colmatadora) e sim por meio de outros instrumentos de preenchimento de lacuna (analogia, princípios gerais de direito, costume). Agir como se legislador (estadual) fosse, isto lhe é vedado.

14. Em suma, na legislação concorrente, a União possui competência limitada ao estabelecimento de normas gerais; os Estados e o Distrito Federal detêm a competência residual para o estabelecimento de normas particulares, competência que lhes é prevista, e, em caso de lacuna - inexistência - de normas gerais, competência plena (normas gerais e particulares) com função colmatadora (isto é, estabelecimento de normas gerais apenas na medida em que estas sejam exigidas para a edição de normas particulares e, obviamente, válidas só no seu âmbito de autonomia). A superveniência de normas gerais federais, porém, torna ineficazes (mas não inválidas) as normas gerais estaduais com função colmatadora. A despeito das regras sobre a legislação concorrente, Estados e Distrito Federal, mas também os Municípios, mesmo estes, que dela não participam, têm ainda a competência suplementar, que os autoriza a estabelecer normas gerais não-concorrentes, mas decorrentes das normas gerais federais; por isso, aliás, esta competência só pode ser exercida em havendo normas gerais da União (não serve para preencher lacunas), devendo existir compatibilidade entre elas (gerais da União e dos Estados/DF) sob pena de invalidade (inconstitucionalidade). 